\title{
ALIMENTOS TRADICIONAIS ENQUANTO ESTRATÉGIA DE SOBERANIA ALIMENTAR: O CASO DO MUNICÍPIO DE BATURITÉ - CEARÁ - BRASIL
}

\author{
Anna Erika Ferreira Lima ${ }^{1}$ \\ Rafaela Maria Temóteo Lima Feuga ${ }^{2}$ \\ Márcia Maria Leal de Medeiros ${ }^{3}$ \\ José Levi Furtado Sampaio ${ }^{4}$
}

Resumo: Um povo para ser livre precisa ser soberano, sendo que essa soberania perpassa pela alimentação. É sobre esta temática que a pesquisa estabeleceu um levantamento de estratégias de soberania alimentar organizadas, especificamente, no Município de Baturité - Ceará. Foram realizadas 12 entrevistas semiestruturadas com representações de movimentos sociais e da sociedade civil. A metodologia etnográfica possibilitou que fossem levantadas estratégias como: casas de semente, quintais produtivos, feiras agroecológicas, PAA, bem como a identificação de quatro alimentos tradicionais reconhecidos pela população. São eles: 1ำ doce de banana em pasta; $2^{\circ}$ bolo pé de moleque; $3^{\circ}$ baião de dois de fava e $4^{a}$ pirão de Fava. Definiu-se o doce de banana em pasta, devido sua colocação no rol das respostas; onde durante 1 mês ocorreu a aplicação de testes de aceitabilidade junto à 100 crianças. Na avaliação, $69 \%$ das crianças relataram "gostei extremamente" o que demonstrou que o doce foi aceito positivamente, demonstrando viabilidade para uma possível inserção na merenda escolar, contribuindo para a redução do desperdício do fruto e para valorização da agricultura local.

Palavras-chave: Soberania Alimentar. Alimentos Tradicionais. Alimentação. Segurança Alimentar. Cultura.

\section{TRADITIONAL FOOD AS A STRATEGY FOR FOOD SOVEREIGNTY: THE CASE OF BATURITE - CEARÁ - BRAZIL}

Abstract: A people to be free needs to be sovereign, and that sovereignty runs through food. It is on this theme that the research established a survey of strategies of food sovereignty organized, specifically, in the Municipality of Baturité - Ceará. Twelve semi-structured interviews were carried out with representations of social movements and civil society. The ethnographic methodology allowed the development of strategies such as: seed houses, productive backyards, agroecological fairs, PAA, as well as the identification of four traditional foods recognized by the population. These are: 1st sweet banana paste; 2nd child foot cake; 3rd baião of two of fava and 4th pyramid of Fava. Banana sweet paste was defined, due to its placement in the list of responses; where for 1 month occurred the application of acceptability tests to 100 children. In the evaluation, $69 \%$ of the children reported "I enjoyed it extremely", which showed that the candy was positively

\footnotetext{
1 Instituto Federal de Educação, Ciência e Tecnologia (IFCE-Campus Fortaleza), Departamento de Turismo, Hospitalidade e Lazer e Programa Associado de Pós-Graduação em Ensino e Formação Docente (PPGEF UNILAB/IFCE), Fortaleza, Brasil, annaerika@ifce.edu.br, https://orcid.org/00000002-8290-9802

2 Instituto Federal de Educação, Ciência e Tecnologia (IFCE-Campus Fortaleza), Departamento de Gastronomia, Fortaleza, Brasil, mleal@ifce.edu.br, https://orcid.org/0000-0003-3570-6954

${ }^{3}$ Instituto Federal de Educação, Ciência e Tecnologia (IFCE-Campus Fortaleza), Departamento de Gastronomia, Baturité, Brasil, rtemoteo@ifce.edu.br, https://orcid.org/0000-0003-2495-053X

${ }^{4}$ Universidade Federal do Ceará (UFC), Programa de Pós-Graduação em Desenvolvimento e Meio Ambiente (PRODEMA-UFC), Fortaleza, Brasil, leviufc@gmail.com, https://orcid.org/0000-0002-29425753
} 
accepted, demonstrating feasibility for a possible insertion in school meals, contributing to the reduction of fruit waste and to the valorization of local agriculture.

Keywords: Food Sovereignty. Traditional Foods. Food. Food Safety. Culture.

\section{ALIMENTOS TRADICIONALES EN CUANTO ESTRATEGIA DE SOBERANÍA ALIMENTARIA: EL CASO DEL MUNICIPIO DE BATURITÉ - CEARÁ - BRASIL}

Resumen: Un pueblo para ser libre necesita ser soberano, siendo que esa soberanía atraviesa por la alimentación. Es sobre esta temática que la investigación estableció un levantamiento de estrategias de soberanía alimentaria organizadas, específicamente, en el Municipio de Baturité - Ceará. Se realizaron 12 entrevistas semiestructuradas con representaciones de movimientos sociales y de la sociedad civil. La metodología etnográfica posibilitó que se plantearan estrategias como: casas de semilla, patios productivos, ferias agroecológicas, PAA, así como la identificación de cuatro alimentos tradicionales reconocidos por la población. Son ellos: $1^{\circ}$ dulce de plátano en pasta; $2^{\circ}$ pastel de pie de moleque; $3^{\circ}$ baião de dos de fava y 4a pirón de Fava. Se definió el dulce de plátano en pasta, debido a su colocación en el rol de las respuestas; donde durante 1 mes ocurrió la aplicación de pruebas de aceptabilidad junto a los 100 niños. En la evaluación, el $69 \%$ de los niños relataron "me gustó enormemente" lo que demostró que el dulce fue aceptado positivamente, demostrando viabilidad para una posible inserción en la merienda escolar, contribuyendo a la reducción del desperdicio del fruto y para la valorización de la agricultura local.

Palabras clave: Soberanía Alimentaria. Alimentos Tradicionales. Alimentación. Seguridad alimentaria. Cultura.

\section{Introdução}

"Quem tem fome, tem pressa!" lema do Sociólogo Herbert de Souza, o Betinho, no início dos anos de 1990 (REDIG; REBOUÇAS, 2014) ganhou força e ressoou, não apenas naquele momento que o Brasil se mobilizou contra os desmandos do Presidente Fernando Collor de Mello, mas em diversos discursos realizados por representantes dos Governos em anos seguintes. Entretanto, o debate sobre a questão alimentar por muito tempo ficou limitado à pauta do acesso a alimentos em quantidade, qualidade e em variedade suficientes à sociedade, sendo este o grande desafio propagado nos programas governamentais de Segurança Alimentar e Nutricional. (VASCONCELOS, 2004).

A Via Campesina, a partir do ano de 1996, protagonizou a pauta que se contrapunha ao conceito de Segurança Alimentar estabelecido pela FAO, pois compreende-se que um povo para ser livre precisa ser soberano e essa soberania passa pela alimentação, sendo necessário se pensar não apenas na produção de alimentos, mas na Soberania Alimentar, indicando que o enfrentamento ao problema de insegurança alimentar requer o reconhecimento de que o atual sistema agroalimentar não tem garantido acesso, disponibilidade e qualidade de alimentos 
Enquanto categoria de análise, esta consiste no direito dos povos a alimentos nutritivos e culturalmente adequados, acessíveis, produzidos de forma sustentável e ecológica e o direito das populações tradicionais de decidirem o seu próprio sistema alimentar e produtivo. A Agricultura Familiar Camponesa é vital para a efetivação dessa proposta e sua implantação vem sendo efetivada por meio de estratégias de Soberania Alimentar independentes ou incentivadas por Organizações NãoGovernamentais (ONG), redes formadas por elas, por universidades, Institutos Federais e também por instituições de pesquisa, gerando demandas para elaboração de políticas públicas.

Podemos indicar o Programa de Aquisição de Alimentos (PAA), as Sementes Crioulas (ou sementes tradicionais), os Quintais Produtivos, as Feiras Agroecológicas e a identificação de alimentos tradicionais como exemplos dessas estratégias de Soberania Alimentar. Experiências como essas têm contribuído para a autonomia do pequeno agricultor familiar camponês ${ }^{5}$, possibilitando a manutenção de variedades tradicionais adaptadas àquelas regiões; além de incentivar a soberania territorial das comunidades, estimular a diversidade de cultivos, diferenciando o cardápio desses grupos e levando ao fortalecimento da organização dos sujeitos envolvidos.

Os alimentos tradicionais (ou alimentos com história) (ZUIN;ZUIN, 2009; BEZERRA, 2014;) se fazem como alternativa para que estes não se percam em virtude da cultura alimentar que vem sendo imposta pelo sistema capitalista, à exemplo das propaganda ligadas às comidas rápidas, os Fast Food e os produtos industrializados, que possuem quantidades alarmantes de aromatizantes e conservantes (ZUIN; ZUIN, 2007; POLLAN, 2017). Esta estratégia também propicia, ainda, o trabalho em família, pois envolve os saberes-fazeres das mulheres, já que são elas as principais produtoras desses alimentos.

Vale ressaltar que a discussão teórica perpassou por leituras na área de Geografia, Ciências Sociais, Gastronomia, Ciência de Alimentos e Antropologia, onde por meio de relatos e vivências junto à comunidades tradicionais camponesas e atividades ligadas ao Instituto Federal de Educação, Ciência e Tecnologia (IFCE -

\footnotetext{
${ }^{5}$ Utiliza-se como referências para compreensão do conceito de campesinato autores como SevillaGuzmán \& Molina (2005), Lima (2008; 2015) e Xavier et.all. (2018), visto que ao estudarem as diversas concepções historicamente construídas identificam como generalidade a relação coevolutiva entre campesinato e natureza, na qual a forma de trabalhar com recursos naturais favorece, em diferentes graus, sua reprodução biótica. Esta categoria histórica, portanto, realiza sua agricultura de maneira distinta à lógica industrial que tem maiores capacidade entrópica e pressão antrópica sobre os ecossistemas.
} 
Campus Baturité); ao grupo Alimentos do Nordeste (ALINE - FACED - UFC) e ao Laboratório de Estudos Agrários e Territoriais (LEAT - UFC) tem sido possível desenvolver pesquisas com objetivo de investigar a Geografia Alimentar do Maciço de Baturité - Ceará - Brasil, tendo em vista identificar alimentos tradicionais que possam ser recompostos como potenciais de geração da segurança alimentar e nutricional, com a proposta desses serem apropriados em suas formas tradicionais, como instrumentos indutores de fortalecimento da agricultura familiar, gerando, assim, renda em função de sua inserção em políticas públicas de alimentação e nutrição, notadamente o Programa Nacional de Alimentação Escolar (PNAE).

É sobre a proposta de identificação dos alimentos tradicionais para que esses sejam incluídos na alimentação escolar no Ceará, enquanto estratégia de soberania alimentar e nutricional, que está alicerçada na proposta de um sistema alimentar pautado na sustentabilidade e que estimule hábitos alimentares saudáveis e que garantam que a cultura alimentar de povos indígenas e comunidades tradicionais seja conservada, que este artigo se materializa, uma vez que será apresentado o estudo de caso do doce banana em pasta; um alimento tradicional elaborado no município de Baturité - Ceará.

Para tanto, serão discutidas categorias de análise como soberania alimentar; agricultura familiar camponesa, alimento e comida; além de debatidas questões como estratégias de soberania alimentar realizadas no Estado do Ceará e o estudo de caso da identificação dos alimentos tradicionais enquanto possibilidade de soberania alimentar para alimentação escolar no Município de Baturité, Ceará Brasil.

\section{Soberania Alimentar E Sustentabilidade: Um Debate Em Pauta}

Discutir a soberania alimentar ${ }^{6}$ é remeter-se invariavelmente ao debate que vem sendo apresentado pela Via Campesina, que desde 1996, consolida-se como uma das articulações responsáveis pela ampliação do conceito e de sua legitimação em âmbito internacional não só como pauta de reivindicação frente aos governos, mas como uma ideia que the permitiu a ampliação de suas lutas políticas no campo

\footnotetext{
${ }^{6}$ Quando se considera a ordem internacional, invariavelmente, o objetivo da Segurança Alimentar e Nutricional se conflita com as questões de soberania, a qual é usualmente trabalhada na perspectiva da soberania nacional (BOBBIO, 1995). Utilizado pelos movimentos sociais, hoje se permite uma leitura diferente do termo soberania, o qual está ligado diretamente a autonomia do ser social. Sua capacidade de escolha e decisão. O ser soberano perpassa, assim, pela capacidade de decisão do para onde ir, o que ler, assistir e inclusive se alimentar.
} 
de suas articulações internacionais e redefinições de agendas de pauta. A noção defendida pela Via Campesina propicia a necessidade de articular diversas dimensões que se relacionam com a produção de alimentos e bens, a reprodução da vida humana e da sustentabilidade do planeta.

Soberania Alimentar é o direito dos povos definirem suas próprias políticas e estratégias sustentáveis de produção, distribuição e consumo de alimentos que garantam o direito à alimentação para toda a população, com base na pequena e média produção, respeitando suas próprias culturas e a diversidade dos modos camponeses, pesqueiros e indígenas de produção agropecuária, de comercialização e gestão dos espaços rurais, nos quais a mulher desempenha um papel fundamental. A Soberania Alimentar é a via para erradicar a fome e a desnutrição a garantia da Soberania Alimentar duradoura e sustentável para os povos (Declaração do Fórum Mundial de Soberania Alimentar, Havana, 2001).

Estes conceitos remetem a um extenso conjunto de relações, com ênfase para o direito dos povos de definir sua política agrária e alimentar, avalizando, assim, o abastecimento de suas populações, a preservação do meio ambiente visando a busca por um desenvolvimento mais sustentável e a proteção de sua produção frente à concorrência com países mais capitalizados de maneira autônoma e soberana. Para Jalil (2009),

[...]a luta pela soberania alimentar se contrapõe à lógica do neoliberalismo repolitizando as esferas políticas e estatal. Relaciona-se a um conjunto de políticas públicas que devem ser articuladas e implementadas, trazendo a dimensão do local como espaço privilegiado e fundamental para a concretização destas políticas em conjunto com o protagonismo e a participação das pessoas, que são efetivamente os sujeitos políticos dos processos de transformação, como uma ação construída 'de baixo para cima' (p.59).

Abaixo segue o Quadro 1 com os argumentos utilizados para adesão ao modelo da soberania alimentar em detrimento do modelo de produção neoliberal (QUADRO 1).

\section{Quadro 1 - Argumentos do modelo da Soberania Alimentar em relação ao modelo neoliberal}

\begin{tabular}{|l|l|l|}
\hline TEMA & $\begin{array}{l}\text { MODELO DOMINANTE } \\
\text { ( NEOLIBERAL) }\end{array}$ & MODELO DA SOBERANIA ALIMENTAR \\
\hline Comércio & Livre comercio & $\begin{array}{l}\text { Alimentos e Agricultura fora dos acordos } \\
\text { Comerciais. }\end{array}$ \\
\hline Prioridade produtiva & Exportação & Mercados locais \\
\hline $\begin{array}{l}\text { Preços dos produtos } \\
\text { Agrícolas }\end{array}$ & $\begin{array}{l}\text { "Lei do mercado"( Não mexer nos } \\
\text { mecanismos que impõem preços } \\
\text { baixos) }\end{array}$ & $\begin{array}{l}\text { Preços justos que cubram os preços de } \\
\text { produção e permitam aos agricultores uma } \\
\text { vida digna. }\end{array}$ \\
\hline Acessos a mercados & Acesso a mercados externos & $\begin{array}{l}\text { Acessos a mercados locais; fim dos } \\
\text { deslocamentos dos agricultores dos seus } \\
\text { próprios devido a indústria agropecuária }\end{array}$ \\
\hline Subsídios & $\begin{array}{l}\text { Enquanto se proíbe no terceiro } \\
\text { mundo são permitidos nos EUA e } \\
\text { EU(apenas aos grandes } \\
\text { agricultores }\end{array}$ & $\begin{array}{l}\text { Os subsídios que não prejudiquem outros } \\
\text { países (através do Dumping) são aceitáveis; } \\
\text { ex..:Garantir que sejam apenas para } \\
\text { agricultores familiares, para comercialização }\end{array}$ \\
\hline
\end{tabular}




\begin{tabular}{|c|c|c|}
\hline & & $\begin{array}{l}\text { direta, apoio de preços, conservação dos } \\
\text { solo, agricultura sustentável, investigação } \\
\text { etc. }\end{array}$ \\
\hline Alimentos & Uma mercadoria & Um direito humano \\
\hline Produzir & Uma opção para os mais eficientes & Um direito dos povos rurais \\
\hline Fome & Fruto da baixa produtividade & $\begin{array}{l}\text { Um problema de acesso e distribuição, fruto } \\
\text { da pobreza e desigualdade. }\end{array}$ \\
\hline Segurança Alimentar & $\begin{array}{l}\text { Consegue-se importando alimentos } \\
\text { de onde sejam mais baratos }\end{array}$ & $\begin{array}{l}\text { Aumenta quando a produção de alimentos } \\
\text { estar nas mãos dos pobres e quando o } \\
\text { alimento se produzem localmente. }\end{array}$ \\
\hline $\begin{array}{l}\text { Controle sobre os produtos } \\
\text { produtivos }\end{array}$ & Privado & Local; controlado pela comunidade. \\
\hline Acesso a terra & Através dos mercados & Através da reforma Agrária \\
\hline Sementes & Uma mercadoria, alvo de patentes. & $\begin{array}{l}\text { Uma herança comum dos povos ao serviço } \\
\text { da humanidade. }\end{array}$ \\
\hline $\begin{array}{l}\text { Créditos e investimentos } \\
\text { rurais }\end{array}$ & Do setor privado & $\begin{array}{l}\text { Do setor publico, dirigidos a agricultura } \\
\text { Familiar }\end{array}$ \\
\hline Dumping & Não é um problema & Deve proibir-se \\
\hline Monopólio & Não é um problema & $\begin{array}{l}\text { A raiz da maior parte dos problemas, os } \\
\text { monopólios devem ser proibidos. }\end{array}$ \\
\hline Sobreprodução & Não existe, por definição. & $\begin{array}{l}\text { Conduz a queda dos preços e leva os } \\
\text { agricultores a pobreza. São necessárias } \\
\text { politicas de maneio das ofertas nos EUA e } \\
\text { EU. }\end{array}$ \\
\hline $\begin{array}{l}\text { Organismos Geneticamente } \\
\text { Modificados }\end{array}$ & São o futuro. & $\begin{array}{l}\text { Perigosos para a saúde e meio ambiente, } \\
\text { uma tecnologia desnecessária, devem ser } \\
\text { proibidos. }\end{array}$ \\
\hline Tecnologia agropecuária & $\begin{array}{l}\text { Industrial; monocultora; } \\
\text { Agrotóxicos, OGMs }\end{array}$ & $\begin{array}{l}\text { Métodos agroecológicos e sustentáveis, não } \\
\text { usa OGMs. }\end{array}$ \\
\hline Agricultores & $\begin{array}{l}\text { Anacronismos; o ineficiente irá } \\
\text { desaparecer. }\end{array}$ & $\begin{array}{l}\text { Guardiões da biodiversidade; } \\
\text { administradores dos recursos naturais, } \\
\text { depositários de conhecimentos. }\end{array}$ \\
\hline
\end{tabular}

Fonte: Adaptado de Rosset (2003).

Conforme Rosset (2003), a soberania alimentar também se constrói com respeito às culturas, tradições, às formas solidárias valorizando a dimensão identitária, ela reforça os laços sociais e interpessoais, incentiva a preservação dos alimentos tradicionais e dos hábitos alimentares culturalmente construídos.

Este debate permitiu aos movimentos camponeses porem como prioridade em suas atividades de formação e nas pautas de reivindicações, temas como preservação da biodiversidade e agroecologia (ROSSET, 2003).

Para além dos movimentos camponeses, o movimento ambientalista, à exemplo das organizações que compõem o Comitê Brasil em Defesa das Florestas e do Desenvolvimento Sustentável, através do debate da soberania alimentar atuam conjuntamente tendo em vista que a preservação dos ecossistemas passa necessariamente pela luta contra a exploração mercantil das riquezas naturais. Nesse sentido é possível identificar movimentos sociais do campo e ambientais 
aliados, uma vez que para o agricultor familiar camponês, terra é lugar onde se quer viver e trabalhar, e ali se estabelecem as relações sociedade-natureza, nas quais o homem necessita dos recursos naturais tanto no presente como para as futuras gerações como preconiza o Princípio da Sustentabilidade, sendo necessária a preservação e a conservação desses sistemas.

$O$ agricultor familiar camponês do qual se fala tem sua base fundamentada na tríade terra-trabalho-família, onde, o campesinato pode ser visto como uma forma social particular de organização da produção. Remetemo-nos, neste caso, a uma agricultura camponesa, cuja base é dada pela unidade de produção gerida pela família (LIMA, 2008; 2015). Esse caráter familiar se expressa nas práticas sociais que implicam uma associação entre patrimônio, trabalho e consumo, no interior da família, e que orientam uma lógica de funcionamento específica.

Para Lima (2008), o viver na e da terra materializa-se, essencialmente, por meio de ocupações, acampamentos, embates, resistências na terra e estratégias de soberania alimentar pelos grupos em situação de vulnerabilidade social ou ambiental, seja tentando garantir sua permanência nesse locus, quanto objetivando o acesso aos que já foram expulsos ou se encontravam na iminência de expulsão.

Nesse contexto, também se destacam os pequenos proprietários que lutam por sua sobrevivência, a qual é ameaçada por contratos de integração com as agroindústrias; por dívidas com bancos e pela falta de apoio do Estado via políticas públicas, condenando-os a uma concorrência, sempre desvantajosa, com os produtores capitalizados.

Estes sujeitos sociais, entretanto, são os protagonistas da maior parcela da produção agrícola no Brasil, ou seja, $70 \%$ do que chega ao prato do brasileiro (FBSSAN, 2013) quando se considera a diversidade de produção e abastecimento no País, visto que o agronegócio se volta, fundamentalmente, à exportação e a produção monocultora. Ou seja, a agricultura familiar camponesa no Brasil caracteriza-se por sua diversidade, seja em produção - aqui se referencia, sobretudo, o acesso aos meios de produção -, seja pelas condições gerais de ingresso aos sistemas que contemplam bens e serviços, além da própria diversidade social a qual esse segmento representa. É o que se nomeia como uma verdadeira coreografia dos sujeitos campesinos, dada suas estratégias de permanência e reprodução no campo. Nesse sentido, não se pretende aqui simplificar ou reduzir a compreensão teórica a respeito desse segmento social, pelo contrário, visa-se 
identificar suas demandas e como estes desenvolvem estratégias diante da busca pela garantia da soberania alimentar.

\section{Estratégias de Soberania Alimentar: Experiências No Estado Do Ceará}

Criado em julho de 1603, o estado cearense é um dos territórios que compõem a Região Nordeste do Brasil, conforme o Mapa 1. O Estado possui uma área territorial de 148.920,538 km2, na qual se encontram 184 municípios, que conforme estimativa do IBGE, atingiu em 2018 a marca de 9.076.426 de habitantes, se mantendo como o $8^{\circ}$ Estado mais populoso do Brasil (DIÁRIO DO NORDESTE, 2018).

Vale destacar que o Estado do Ceará caracteriza-se por ter uma estrutura fundiária e de produção agrícola baseada em pequenas propriedades de subsistência, que historicamente foram negligenciadas pelas políticas de desenvolvimento do setor ao longo do último século. Frisa-se o fato de existir uma homogeneidade significativa na distribuição das terras em todo o estado, com aproximadamente $10 \%$ em propriedades menores de 10 ha, $30-35 \%$ em propriedades de 10 a 100 ha, e 40\% para propriedades acima de 100 ha. Existindo um número reduzido de propriedades maiores de 1000 ha no estado (IBGE, 2006).

Conforme o Ministério da Agricultura, Pecuária e Abastecimento (MAPA, 2016), o Ceará ocupa o quarto lugar no ranking dos estados brasileiros com o maior número de estabelecimentos familiares, o que corresponde a $90 \%$ das unidades rurais do estado, ou ainda, 341.510 propriedades familiares. Os dados são do Censo Agropecuário do Instituto Brasileiro de Geografia e Estatística (IBGE) de 2006, onde se observam que os agricultores familiares cearenses são responsáveis pelo cultivo de $91 \%$ do feijão, $89 \%$ do milho grão, $88 \%$ do arroz em casca e $82 \%$ da mandioca e $81 \%$ da criação de suínos no estado.

Essa diversidade de produções agrícolas voltadas, principalmente, para o abastecimento interno do Estado, viabiliza estratégias de resistência às condições climáticas adversas, uma vez que mais de $90 \%$ do Território Cearense se encontra no Semiárido. As estratégias que constam nos tópicos seguintes se caracteriza por combinar os saberes populares com saberes científicos, são frutos de construções envolvendo diversos sujeitos sociais e, decorrente das constantes reivindicações dos movimentos encontravam-se nos últimos Governos, gradativamente, se fortalecendo como políticas públicas. Contudo, elas serão mais impactantes de forem adotadas em conjunto seguindo o princípio da intersetorialidade (LIMA, 2015), 
que conforme Junqueira (1997), este é caracterizado pela articulação de saberes e experiências no planejamento, a realização e a avaliação de ações, com o objetivo de alcançar resultados integrados em situações complexas, visando a um efeito sinérgico no desenvolvimento social.

\section{a) Sementes Crioulas}

As sementes crioulas, ou sementes tradicionais, foram selecionadas ao longo dos séculos nos quintais e nas roças, por povos tradicionais como índios, quilombolas e os camponeses, tendo sido adaptadas ao nosso ambiente evolutivamente, fazendo parte da vida e da cultura desses grupos sociais em diversas regiões.

As Casas de Sementes surgem na Região Nordeste, na década de 1970, por iniciativa da Igreja Católica, a partir do quadro desolador da seca, de repressão dos grupos sociais camponeses e da necessidade de organização.

As ações de criação e difusão das Casas de Sementes no Ceará foram reforçadas a partir de 1986 através do Centro de Pesquisa e Assessoria. Responsável (ESPLAR) e posteriormente, a partir de 1991. Essa atuação foi potencialidade com o apoio da Rede de Intercâmbio de Sementes (RIS). Hoje, a RIS possui uma articulação composta por aproximadamente 177 Casas de Sementes Comunitárias (RIS, 2010). Dessas, há 29 casas de sementes onde estão cadastrados 639 camponeses. O trabalho é desenvolvido nas comunidades rurais com apoio da Cáritas Diocesana de Sobral em parceria com Sindicato dos Trabalhadores Rurais, Associações Comunitárias, Instituto Carnaúba, Banco do Nordeste/ETENE e Embrapa Caprinos e ESPLAR - Centro de Pesquisa e Assessoria.

Para Vasconcelos (2011) as casas de sementes funcionam através do sistema de depósito e empréstimo, havendo um calendário de reuniões mensal, uma coordenação local responsável pelo registro das atas de reuniões e pelo cadastro de sócios, bem como a organização no período de distribuição das sementes para o plantio e devolução após o período da colheita.

As Casas de Sementes garantiram a autonomia do agricultor; contribuíram para manter as variedades tradicionais, adaptadas àquele microclima; contribuíram para a Segurança Alimentar das comunidades, possibilitando a diversidade de cultivos e também fortaleceram a organização dos grupos. De fato as Casas de Sementes, tornou-se um importante espaço de reuniões, conversas e debates sobre os problemas das comunidades, bem como uma forma exitosa de garantia de 
produção dos alimentos tradicionais de forma sustentável, visto que àqueles que se utilizam das sementes, são devem repor seu empréstimo.

\section{b) Quintais Produtivos}

Quintais produtivos é uma tecnologia social que combina os saberes tradicionais e agroecológicos. Ela resgata toda a simbologia dos quintais, o espaço de terreno ao redor da casa, tradicionalmente usados como extensão das atividades domésticas. Neles são cultivadas frutas, hortaliças, plantas medicinais, temperos, plantas ornamentais e são criados pequenos animais. Foram nos quintais que as mulheres domesticaram as sementes e raízes que deram origem à agricultura (AZEVEDO, 2007). Esta tecnologia resgata e dá visibilidade ao trabalho das mulheres. Os quintais tradicionais são, também, locais de brincadeiras, de preparativos de festas, de encontros. Cores, cheiro e sabores se misturam nos quintais, nas memórias e nas vidas das pessoas.

A possibilidade de preservar e ao mesmo tempo ampliar a diversidade de alimentos, preservando os recursos naturais e garantindo a saúde humana representa uma possibilidade de fundamental importância para a soberania e segurança alimentar e nutricional da família. Nessa perspectiva várias organizações governamentais e não governamentais estão participando da implantação de quintais produtivos no Ceará, um exemplo é o CETRA (LEONEL, 2010) que desenvolve o projeto 'Quintais para a Vida' no qual promove a combinação dos quintais com a as cisterna e as feiras agroecológicas.

\section{c) Feiras Agroecológicas}

As Feiras Agroecológicas se constituem como espaço de comercialização dos produtos da agricultura familiar combinando métodos e princípios da agroecologia e da sócioeconomia solidária. Com esta denominação poderemos encontrar várias feiras no Ceará como as de Apuiarés, Itapipoca, Paracuru, Quixadá, Trairi e Tururu, assistidas pelo Centro de Estudos do Trabalho e de Assessoria ao Trabalhador (CETRA); de Crato, apoiada pela Associação Cristã de Base (ACB); Feira Agroecológica do Benfica, apoiada por várias entidades dentre elas o Terrazul e o Instituto Kairós.

A comercialização direta dos produtos da agricultura familiar podem receber várias denominações como feiras da agricultura familiar, feiras agroecológicas e de socioeconomia solidária, como a Rede Bodega, organizadas pela Rede Cáritas e as feiras distritais animadas pelas Dioceses. Todas buscam solucionar 0 antigo problema vivenciado pelo agricultores/as familiares referente à garantia de preços 
justos na comercialização de seus produtos. Revelam-se, ainda, uma forma de dar visibilidade aos produtos que escoavam através de atravessadores.

Estas feiras são espaço de resgate cultural e da diversidade alimentar, resultado do processo de organização social dos agricultores e agricultoras, estimulando as relações de solidariedade entre produtores e consumidores, trocando e construindo saberes coletivos (CETRA, 2012).

\section{d) Programa de Aquisição de Alimentos}

O Programa de Aquisição de Alimentos (PAA), que foi instituído em 2003, através de proposição do Conselho Nacional de Segurança Alimentar e Nutricional (CONSEA), com a finalidade de promover a inclusão social e econômica no campo por meio do fortalecimento da agricultura familiar, através de mecanismos de comercialização nos próprios locais de origem, a preços justos, e promover o acesso a alimentos às populações em situação de insegurança alimentar.

Este programa foi concebido como parte de uma politica estruturante, incluindo também a formação de estoques estratégicos para o abastecimento do mercado institucional de alimentos, que compreende as compras governamentais de gêneros alimentícios para fins diversos, e ainda permite aos agricultores familiares que estoquem seus produtos para serem comercializados a preços mais justos, sem a presença do atravessador.

O Programa se propõe a incorporar as questões de gênero e étnico-raciais, contribuindo para a superação das causas da miséria e da fome (BRASIL, 2012). Foi a partir desta constatação que a Câmara Temática de Produção e Abastecimento (CTPA), instância do Conselho de Segurança Alimentar e Nutricional do Ceará (CONSEA CEARÁ), priorizou o exercício do controle social deste programa.

O PAA é operacionalizado com recurso do Ministério do Desenvolvimento Social e do Ministério do Desenvolvimento Agrário, sendo executado em parceria como os Estados, Municípios e Companhia Nacional de Abastecimento (Conab). O Programa compra os alimentos de agricultores familiares, com isenção de licitação, a preços compatíveis aos praticados nos mercados regionais, através de quatro modalidades: Compra Direta, Formação de Estoques pela Agricultura Familiar, Compra com Doação Simultânea, PAA leite. Os produtos adquiridos são destinados às entidades da rede socioassistencial; equipamentos públicos de alimentação e nutrição; famílias em situação de vulnerabilidade social e para a formação de cestas de alimentos distribuídas a grupos populacionais específicos. 
No Ceará são praticadas todas estas modalidades. O Consea Ceará acompanha as mesmas, entretanto iniciou a construção de metodologias, para um efetivo controle social, especificamente ao que é executado pela Conab. No ano de 2012, foram analisados 121 projetos, procedentes de 59 municípios. Os projetos envolveram um montante de recursos de $R \$ 11.700 .191,25$ e 3.693,552, 400 toneladas de alimentos. Dentre os projetos analisados, 85 foram aprovados. Destes, 31 foram aprovados com modificações. O total geral dos projetos aprovados

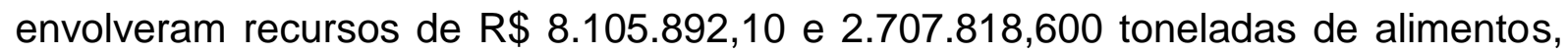
adquirindo alimentos de 2.064 produtores/as familiares, sendo 735 mulheres e 1.329 homens. Os alimentos serão entregues para 835 entidades consumidoras e atenderão a um total de 316.437 pessoas.

\section{Alimentos Tradicionais Enquanto Possibilidade De Soberania Alimentar $\mathrm{Na}$ Alimentação Escolar: O Doce De Banana Em Pasta No Município De Baturité - CE}

Um alimento tradicional estaria ligado a sua origem geográfica? Ou a sua tradição e permanência? Seria ao processo de manufatura? Talvez o tipo de matéria-prima utilizada? Ou a tudo isto? Para Tibério (1998), falar em alimentos tradicionais, não é pensar em produtos massificados, produzidos de forma intensiva ou industrial, sem qualquer tipo de diferenciação. Por essa razão, os alimentos tradicionais também estão ligados ao saber-fazer do agricultor, isto é, a forma com a qual ele processa (saber-fazer) o alimento, em conjunto com a qualidade ímpar das suas matérias-primas. Assim o alimento produzido e consumido em cada região passou a ser mais uma diferenciação entre as diversas culturas, o que tornou os costumes gastronômicos e os alimentos sinais de identidade de cada população.

Dessa forma, esses produtos também são chamados de tradicionais, artesanais, caseiros, de qualidade, produtos da terra, entre outras denominações. Isto posto, os alimentos tradicionais podem ser definidos como sendo "um produto único pelo emprego de matérias-primas e pelos conhecimentos aplicados, assim como os usos de produção, de consumo e de distribuição e que atualmente recebem, entre outras, as denominações de local, artesanal ou regional" (RIBEIRO; MARTINS,1995).Portanto, esses alimentos são tradicionais porque persistem no tempo, sendo sempre produzidos em um determinado lugar e de uma determinada maneira, conservando características que os definem quanto ao aspecto, à textura e ao sabor que estão ligados à cultura gastronômica de uma população. 


\section{A importância dos alimentos tradicionais}

Os alimentos tradicionais, também são denominados produtos ou alimentos com história, pois se constituem e fazem parte da história social de uma determinada cultura. Vindos de um longo tempo, através de gerações que os foram produzindo e recriando, esses produtos marcam um processo que reúne relações sociais e familiares, num encontro entre o saber e a experiência; portanto, a produção desses alimentos é, ainda, uma arte construída ao longo do tempo através da tradição familiar (RIBEIRO; MARTINS, 1995)

A produção de alimentos tradicionais propicia, ainda, o trabalho em família, pois envolve os saberes-fazeres das mulheres, já que são elas as principais produtoras desses alimentos. Por tais razões, nos últimos anos surgiu na Europa um movimento denominado Slow Food que pretende resgatar as tradições relacionadas ao alimento e a seu consumo (ZUIN;ZUIN, 2007). Tradições essas que estão sendo esquecidas como, por exemplo, o prazer de se alimentar, utilizando produtos artesanais de qualidade especial, que são manufaturados de forma que se respeite tanto o meio ambiente quanto as pessoas responsáveis pela produção, ou seja, os produtores e sua cultura. Diante disso, a produção desses alimentos seria uma alternativa para o desenvolvimento local, assegurando aos pequenos produtores a valorização de sua cultura, de sua história e de sua produção (ZUIN;ZUIN, 2007).

Por meio da produção de alimentos tradicionais, o produtor rural de pequeno porte pode afastar-se da marginalização social, pois a identidade cultural presente nos produtos locais e regionais pode emancipá-los economicamente, dando-lhe a liberdade de plantar e escolher seus gêneros alimentícios.

Enfatizamos, assim, a arte do alimento tradicional e suas perspectivas comerciais/sociais, como forma de impulsionar o comércio local, já que grande parte dos pequenos produtores rurais vive com grandes dificuldades. Diante disso, é frequente a migração dos filhos desses produtores para os centros urbanos na busca de melhores condições financeiras, negando assim a sua cultura. No Brasil, são poucas as regiões que ainda conservam as tradições e cultivam a produção de alimentos tradicionais.

Muito da nossa cultura alimentar tem se perdido, como destacado anteriormente. $\mathrm{O}$ que é comida e alimento se misturam em meio à uma lógica alimentar capitalista. É sobre essa diferenciação que o tópico subsequente se materializa. 


\section{Compreendendo o que é alimentação, comida e alimento}

Torna-se necessário ainda compreender concepções de alimentação, comida e alimento, cultura alimentar, práticas alimentares, alimentar e nutricional, buscando precisar conceitos e categorias, um cuidado metodológico indicado por Maciel (2004, p. 26). Em busca dessa precisão conceitual, considera-se que as concepções de alimento e comida, na perspectiva das Ciências Humanas, extrapolam o aspecto nutricional. De acordo com Santos (2005, p. 12),

O alimento constitui uma categoria histórica, pois os padrões de permanência e mudança dos hábitos e práticas alimentares têm referência na própria dinâmica social. Os alimentos não são somente alimentos. Alimentar-se é um ato nutricional, comer é um ato social, pois constitui atitudes ligadas aos usos, costumes protocolos, condutas e situações. Nenhum alimento que entra em nossas bocas é neutro.

Com suporte em uma compreensão próxima e complementar à Santos (2007), os conceitos de comida e alimento elaborados por DaMatta (1997) e Maciel (2004) apresentam a perspectiva da Antropologia. DaMatta (1986; 1997) concebe comida como um importante "código de expressão da sociedade brasileira", tanto quanto a política, a economia, a família, o espaço e o tempo. Diferencia comida de alimento, acentuando que o alimento é uma categoria mais ampla, que abrange $o$ universo daquilo que pode ser ingerido para manter a vida biológica. E comida está relacionada a escolhas feitas dentro desse universo, guiadas pelo prazer e por normas de comunhão e comensalidade. Maciel (2004, p. 26) assinala que:

Alimentação refere-se a um conjunto de substâncias que uma pessoa ou
grupo costuma ingerir, implicando a produção e o consumo, técnicas e
formas de aprovisionamento, de transformação e de ingestão de alimentos.
Deste modo, alimentação vai além do biológico, relacionando com o social e
o cultural.

Toma-se cultura alimentar como "el conjunto de representaciones, de creencias, conocimientos y de prácticas heredadas y/o aprendidas que están asociadas a la alimentación e que son compartidas por los individuos de una cultura dada o de um grupo social determinado dentro de una cultura". (CONTRERAS; ARNAIZ, 2005, p. 37). Sendo uma proposta de estudo sobre alimentos tradicionais, compreendidos como um dos aspectos imediatos e central da existência humana, pressupõe-se que os mesmo são carregados de valores simbólicos, fonte para entendimento de laços de pertença social e de solidariedade, de aspectos da dinâmica social. Dos seus rituais de produção, preparação e consumo, emergem 
sua dimensão cultural, sua acepção como comida e de elemento definidor de identidade.

Comida é cultura quando é preparada, porque, uma vez adquiridos os produtos-base, da sua alimentação, o homem os transforma mediante o uso do fogo e de uma elaborada tecnologia que se exprime nas práticas de cozinha. Comida é cultura quando consumida, porque embora o homem podendo comer de tudo, ou talvez justamente por isso, na verdade não come qualquer coisa, mas escolhe a própria comida, com critérios ligados tanto às dimensões econômicas e nutricionais do gesto quanto aos valores simbólicos de que a própria comida se reveste. Por meio de tais percursos, a comida se apresenta como elemento decisivo da identidade humana e como um dos mais eficazes instrumentos para comunicá-la. (MONTANARI, 2008, p. 16).

Mas o que está sendo ofertado na merenda escolar para as crianças? As propagandas cada vez mais atrativas com comidas coloridas, mais aromatizadas e com sabores marcantes e excessivamente residuais (doces ou salgados ) têm induzido à formação de demandas nas residências brasileiras que levam às famílias a optarem pela aquisição de produtos facilmente manipulados e com preços cada vez mais altos como forma de atender essas "necessidades" de crianças e adolescentes.

\section{Dentre as possibilidades...: 0 doce de banana em pasta e sua aceitabilidade em uma escola pública no município de Baturité - Ceará}

Desde a época da colonização a alimentação no Ceará era baseada em grande parte de origem animal: bovinos, ovinos, caprinos e suínos (BEZERRA, 2014). O leite - proveniente das vacas e cabras - era consumido in natura, em forma de queijo, doce, coalhada, nata, manteiga, ou acompanhado de farinha de mandioca, cuscuz ou mungunzá. Nas margens dos rios, passado o inverno, plantava-se batata doce, melancia e jerimum. No litoral o peixe estava presente em todas as refeições do pescador, até no café da manhã aliado à farinha. Seu preparo ocorria a partir de cozimento, podendo ser assado, ou mesmo um ensopado; acompanhado de pirão de farinha de mandioca escaldada, ou farinha de mandioca crua.

Utilizados para adoçar ou como ingredientes em bolos e quitutes, os derivados da cana de açúcar - mel, alfenim, batida e principalmente a rapadura tinham presença marcante na mesa do cearense. Fazia às vezes de açúcar, adoçando o café e o leite; ou raspada, quando era acompanhamento da coalhada e até de pratos salgados como o cuscuz e o feijão.

As frutas eram raras no sertão, mas abundantes nas regiões de serra úmida, onde havia banana, sapoti, manga, jaca e laranja. Além do consumo natural, com 
elas as quituteiras preparavam doces diversos e licores. Do caju, se aproveita tudo: o pedúnculo comido ao natural ou transformado em doces, compota, cajuína, suco. As castanhas se assavam na brasa em fogareiros improvisados, embaixo dos mesmos cajueiros onde haviam sido colhidos (MORAIS, 2009).

A farinha de mandioca era indispensável em refeições a base de leite, mingau, pirão e farofa e usada também como ingrediente em bolos, assim como o amido da mandioca transformado em goma e recomposto no preparo do beiju, da tapioca e de iguarias doces como bulins (fogosas), broas e filhoses. De origem indígena, o uso da mandioca na alimentação teve início nas fazendas, que dispunham de "casa de farinha", instalada próximo à casa grande. Ali era feito a "desmancha" da mandioca, separando a parte comestível da manipueira, líquido venenoso contido no tubérculo (DENARDIN; KOMARCHESKI, 2015).

Devido aos conhecimentos e saberes-fazeres presentes nesses alimentos, através de gerações, a sua produção resgata não só a história envolta neles, mas o caráter histórico do próprio produtor o que contribui diretamente para a resistência de comunidades tradicionais. Nesse sentido, delineamos alguns aspectos que evidenciam a importância de se produzir esses tipos de alimento, como a garantia de acesso a esses por crianças que vivem em Baturité, bem como, o fortalecimento do mercado por produtos diferenciados, para o desenvolvimento econômico dos produtores e de sua região.

As regiões do Ceará delineiam especificidades que tornam-nas peculiares. Ou seja, pensar no Território do Maciço de Baturité (Mapa 1), o qual compreende uma área de $3.709 \mathrm{~km}^{2}$ e é composto por 13 municípios $^{7}$ (IPECE, 2017) e se voltar, especificamente, para o município de Baturité; remete à suas características ambientais que se expressam no sertão e na serra, o que permitem identificar costumes alimentares a partir do consumo de frutas e verduras características dessas duas unidades ambientais.

\footnotetext{
7 Os municípios que compõem Território Maciço de Baturité são: Palmácia, Pacoti, Guaramiranga, Mulungu e Aratuba (Micro Território I); Baturité, Capistrano, Itapiúna, Aracoiaba, Redenção e Acarape (Micro Território II); e pelo Micro Território III que contempla os municípios de Ocara e Barreira.
} 
Mapa1: Localização do Maciço de Baturité no Estado do Ceará (2017)
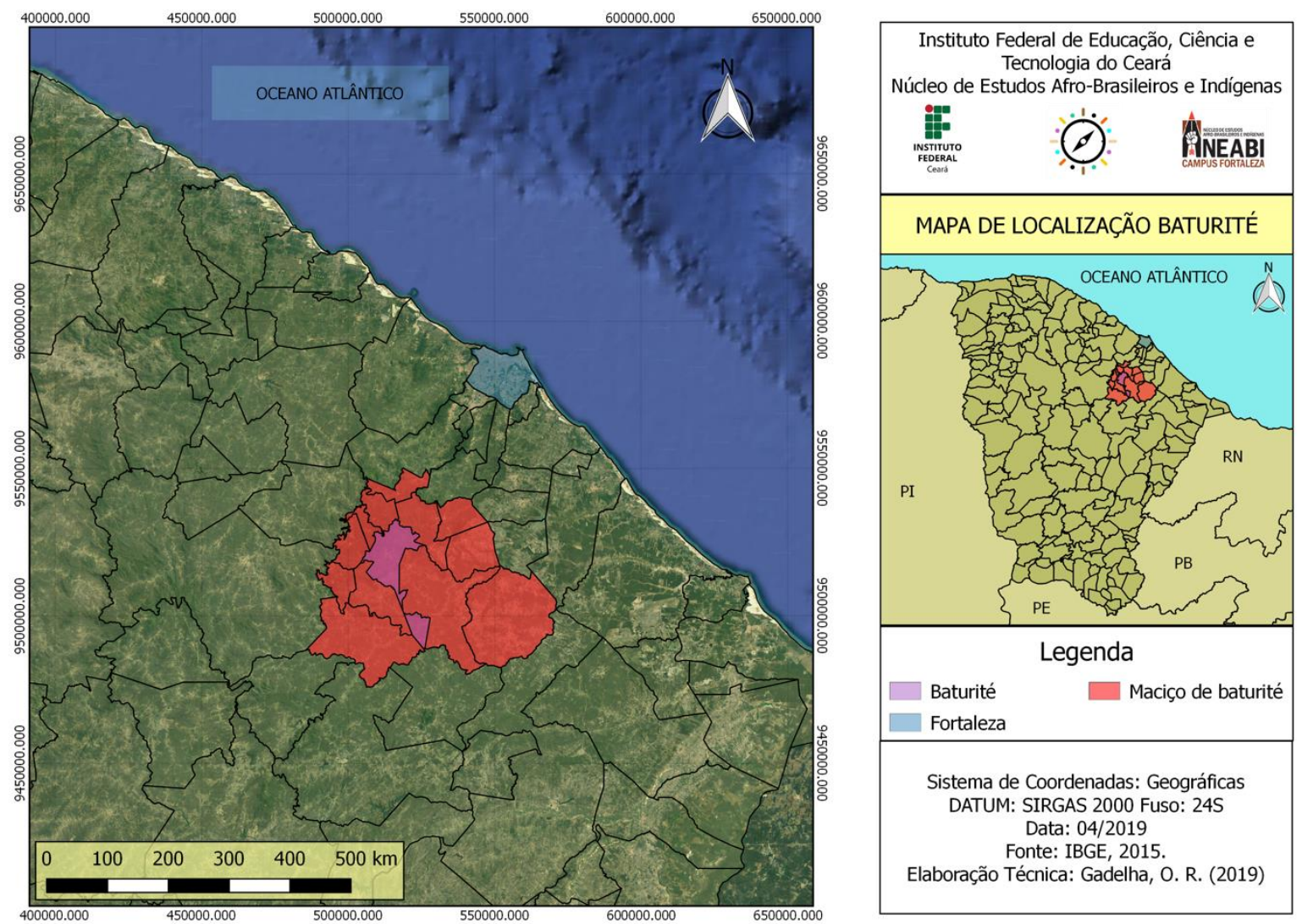

Fonte: Elaborado por Gadelha, O.R. (2019)

No caso dessa fase da pesquisa foi observado que a banana é um produto expressivamente consumido neste Território, sendo a mesma encontrada em abundância na Serra, enquanto que o uso da mandioca se efetiva, principalmente, nas áreas semiáridas dessa Região, ou seja, no Sertão.

Para Souza (2011), a Serra de Baturité constitui um dos mais importantes enclaves de mata úmida do Ceará. Representa um ambiente de exceção do bioma caatinga e é o principal centro dispersor de drenagem que converge para Região Metropolitana de Fortaleza (RMF) (BASTOS, 2011).

Durante o levantamento dos alimentos tradicionais, especificamente os do município de Baturité (Mapa 1), que possui cerca de 33.321 habitantes (IBGE, 2018) e 1.933 agricultores familiares (IBGE, 2006), foi realizada a aproximação com agricultores familiares camponeses; donas de casa e cozinheiras do município. Um total de doze entrevistas foram realizadas, percebendo-se partir desses relatos, que seria necessário focar em dois alimentos, ou seja, dada a representatividade dos mesmos nos relatos catalogados no período de três meses. Nesse sentido foi identificado o uso regular da banana, base para o doce de banana em pasta, além da jaca, esta que será foco de um outro processo de pesquisa. 


\section{Por onde se andou...}

Os registros aconteceram na forma escrita, em diário de campo e através de imagens, obtidas com filmagens e fotografias as quais possibilitam que o objeto de estudo fosse recuperado e recriado por intermédio da memória dos informantes, com vistas a constituir um quadro de referência para o desencadeamento da etapa etnográfica, com suas técnicas de coletas de dados, observação participante e registro orais, que visaram gerar uma descrição densa (GEERTZ, 1973; 1978).

Destarte frisar que os testes de aceitabilidade aplicados durante os construtos da pesquisa foram fundamentados na metodologia do Programa Nacional de Alimentação Escolar (PNAE), coordenado pela Coordenação Geral do Programa de Alimentação Escolar (CGPAE), o qual criou em 8 de dezembro de 2006, por meio da Portaria no 362, um Grupo de Trabalho (GT) para que todo alimento que se pretenda incluir na merenda escolar deverá ser analisado sensorialmente em escolas públicas através do teste de aceitabilidade que é o conjunto de procedimentos metodológicos, cientificamente reconhecidos, destinados a medir o índice de aceitabilidade da alimentação oferecida aos escolares.

O Grupo de Trabalho do PNAE adotou como testes a serem utilizados para avaliar a aceitação da alimentação escolar dois métodos: o resto ingestão (avaliação de resto) e a escala hedônica. Tais métodos foram escolhidos pelo fato de serem os mais utilizados no país e suas aplicações serem viáveis no ambiente escolar. Também ficou definido a utilização da escala hedônica de cinco pontos e uma amostra de 100 a 500 alunos para aplicação dos testes.

Nesse contexto, foi aplicado o referido teste de aceitabilidade para avaliar a aceitação do doce de banana em massa através de testes de análise sensorial na Escola de Ensino Fundamental e Médio Domingos Sávio, uma escola municipal de Baturité. Os testes de aceitabilidade foram aplicados através de ficha de avaliação, onde 100 crianças na faixa etária de 11 a 14 anos, estudantes do ensino fundamental, avaliaram o doce de banana utilizando escala hedônica verbal de cinco pontos, descritas a seguir: gostei extremamente; gostei ligeiramente; indiferente; desgostei ligeiramente e desgostei extremamente. Foram acrescentadas ao teste de aceitabilidade duas perguntas para justificar os valores de alta ou baixa aceitação: - Diga o que você mais gostou na preparação/- Diga o que você menos gostou na preparação. 
Para avaliar a aceitação do doce de banana em massa foram realizados testes de análise sensorial na Escola de Ensino Fundamental e Médio Domingos Sávio, escola da rede municipal de Baturité, Ceará.

No dia seguinte, o bolo e o doce foram levados para Escola de Ensino Fundamental e Médio Domingos Sávio, escola da rede municipal de Baturité, Ceará. Foram selecionados cem alunos de idade escolar entre 11 e 14 anos, para fazer a degustação do bolo pé-de-moleque e do doce de banana em massa.

A aplicação dos testes foi realizada nas salas de aulas, em condições ambientais usuais, no turno da manhã aproximadamente uma hora antes da merenda escolar. Procurou-se manter o melhor nível possível de organização e afastamento das carteiras para que os provadores tivessem a individualidade necessária para participação nos testes. A duração média das aplicações foi de 5 a 10 minutos, sendo de 15 a 20 minutos o período de permanência na sala.

A equipe de aplicação foi composta por três instrutores. Os instrutores fizeram revezamento de tarefas (informações e explicações, distribuição de água e distribuição das amostras) nas diferentes salas de aula.

A escolha pela elaboração do doce de banana em pasta se deu pelos resultados obtidos com a aplicação de cinquenta questionários no município de Baturité (2011), que indicaram quatro alimentos como tradicionais, ou ainda, que para os entrevistados, dão identidade para a Região do Maciço de Baturité. Seriam esses em suas respectivas ordens: $1^{\circ}$ doce de banana em pasta; $2^{\circ}$ bolo pé de moleque; $3^{\circ}$ baião de dois de fava e $4^{a}$ pirão de Fava.

A escolha para esta pesquisa, ou seja, o doce de banana em pasta, ocorreu também pela sua praticidade e aceitação dos entrevistados em considera-lo como um alimento tradicional.

\section{O fazer e o degustar: considerações sobre o processo de elaboração do doce de banana em massa}

Para o cearense, é tradicional o hábito de "adoçar a boca" após as refeições. E para isso, sempre houve uma variedade de doces, entre os quais, constam os de leite, goiaba, caju, banana, mamão com coco, entre outros. A receita do doce em questão foi apresentada pela D.M. (76 anos) ${ }^{8}$, nascida na cidade de Redenção e residente na cidade de Baturité.

8 A identidade dos entrevistados foi mantida em sigilo, sendo utilizada apenas iniciais dos seus nomes. 
De acordo com a Resolução Normativa n.ำ 9, de 11 de dezembro de 1978, doce em pasta é o produto resultante do processamento adequado das partes comestíveis desintegradas de vegetais com açúcares, com ou sem adição de água, pectina, ajustador do $\mathrm{pH}$ e outros ingredientes e aditivos permitidos por estes padrões até uma consistência apropriada, sendo finalmente, acondicionado de forma a assegurar sua perfeita conservação. O doce em pasta é dito em massa quando a pasta for homogênea e de consistência que possibilite o corte.

Para a elaboração do doce em massa de banana utilizou-se aproximadamente quinze quilos de banana e seis quilos de açúcar. As bananas foram adquiridas no mercado local do município de Baturité, Ceará um dia antes do preparo do doce. As mesmas apresentavam-se em estado maduro, com a casca amarelada e alguns pontos escuros. Foram descascadas manualmente, selecionando aquelas que estavam sem manchas e injúrias. Para otimização no processo de cozimento, foram processadas em moinho manual, obtendo assim uma polpa com pequenos fragmentos e homogeneizada.

O cozimento das bananas com o açúcar foi realizado em tacho de alumínio grande em fogo à lenha montado no chão do quintal de DM (76 anos). A polpa foi mexida constantemente para que o mesmo não grudasse no tacho. Após esse período, deu-se início o processo de fervura da polpa, que ocorre cerca de uma hora após o início do cozimento.

A polpa foi homogeneizada com mais vigor, pois a mesma começa a apresentar mais viscosidade e com facilidade grudava no tacho. Cerca de meia-hora depois, o doce ganhou formato, apresentando a massa uma viscosidade elevada e coloração bem escura.

O doce de banana foi envasado a quente em recipientes de vidro, previamente higienizados e sanitizados, com vistas a conservar por um maior tempo o doce.

\section{Doce de Banana - Teste de Aceitabilidade}

Somente em 1994, quando ocorreu a descentralização do Programa de Merenda Escolar, transferindo o poder de compra dos alimentos para as administrações locais, verificou-se uma melhora na aceitabilidade da alimentação escolar, com maior diversidade do cardápio e a inclusão dos alimentos in natura, além de se observar a valorização e o respeito aos hábitos alimentares dos estudantes (MARTINS et al, 2004). 
Ao longo dos anos, o Programa Nacional de Alimentação Escolar (PNAE) vem regulamentando, pelas Resoluções do Fundo Nacional de Desenvolvimento da Educação, a aplicação de testes de aceitabilidade. Em 25 de agosto de 2000 normatizou-se a Resolução/FNDE/CD n 15 que tratava em seu capítulo IV, art. 6, que os testes de aceitabilidade deveriam ser aplicados apenas quando introduzido no cardápio da alimentação escolar novos alimentos, estabelecendo também que o índice de aceitabilidade não poderia ser inferior a $70 \%$, sendo necessário ser observado na aplicação do teste parâmetros técnicos, científicos e sensoriais reconhecidos.

Dois anos depois, uma nova Resolução (Resolução/FNDE/CD nº 002 de Janeiro de 2002) modifica o índice de aceitabilidade, não podendo ser inferior a 85\%. Posteriormente, a Resolução/FNDE/CD n 32 de agosto de 2006, mantém o índice de aceitabilidade em 85\% e vem reforçar a necessidade da aplicação do teste de aceitabilidade que deverá ocorrer sempre que houver a introdução de alimento atípico ao hábito alimentar local, em qualquer inovação e alteração do cardápio ou para avaliar a aceitabilidade dos cardápios oferecidos com maior frequência.

Cabe ressaltar, que através da Medida Provisória n² 2.178-36 de 24 de agosto de 2001 ficou estabelecido a não autorização do repasse dos recursos do PNAE aos Estados, Distrito Federal e Municípios que, entre outras determinações, não aplicarem testes de aceitabilidade e não realizarem controle de qualidade dos produtos adquiridos com os recursos do PNAE, ou o fizerem em desacordo com a regulamentação aprovada pelo FNDE.

Contudo, a ausência de definição de um método a ser utilizado levou as unidades executoras ao não cumprimento integral das referidas normas. Esse fato contribuiu para criação em 8 de dezembro de 2006, por meio da Portaria № 362, o Grupo de trabalho (GT) denominado: "Aplicabilidade do teste de aceitabilidade nos alimentos destinados ao Programa Nacional de Alimentação Escolar", coordenado pela Coordenação Geral do Programa de Alimentação Escolar (CGPAE).

A partir de então, para o PNAE, o teste de aceitabilidade é o conjunto de procedimentos metodológicos, cientificamente reconhecidos, destinados a medir 0 índice de aceitabilidade da alimentação oferecida aos escolares.

O Grupo de Trabalho do PNAE adotou como testes a serem utilizados para avaliar a aceitação da alimentação escolar dois métodos: o resto ingestão (avaliação de resto) e a escala hedônica. Tais métodos foram escolhidos pelo fato 
de serem os mais utilizados no país e suas aplicações serem viáveis no ambiente escolar.

Para avaliar a aceitação do doce de banana em massa foram realizados testes de análise sensorial na Escola de Ensino Fundamental e Médio Domingos Sávio, escola municipal de Baturité, Ceará. Os testes de aceitabilidade foram aplicados através de ficha de avaliação, onde 100 crianças na faixa etária de 11 a 14 anos, estudantes do ensino fundamental, avaliaram o doce de banana utilizando escala hedônica verbal de cinco pontos, descritas a seguir: 1)gostei extremamente; 2)gostei ligeiramente; 3) indiferente; 4) desgostei ligeiramente; e 5) desgostei extremamente.

Foram acrescentadas ao teste de aceitabilidade duas perguntas para justificar os valores de alta ou baixa aceitação:

- Diga o que você mais gostou na preparação.

- Diga o que você menos gostou na preparação.

Para cada uma das crianças foi entregue amostra do doce de banana servido em copo descartável pequeno, juntamente com um copo com água. As crianças foram orientadas a primeiro consumirem água, para limpeza do palato e posteriormente, o consumo do doce.

$\mathrm{Na}$ avaliação, 69\% das crianças relataram "gostei extremamente" do produto e $21 \%$ delas que "gostei ligeiramente".

Esta realidade deve-se ao fato da região do Maciço de Baturité, onde está inserido o município em questão, ser uma grande produtora de banana, com consumo cotidiano pela população, principalmente por crianças. Frente a esses resultados, o doce de banana em pasta foi aceito positivamente pelos alunos, com índices promissores para uma possível inserção na merenda escolar (90\%), contribuindo para a redução do desperdício do fruto na região e valorização da agricultura familiar local.

Os resultados do referido teste de aceitabilidade foram essenciais para a discussão da inclusão deste alimento no cardápio da escola. Entretanto, ainda é possível deparar-se com problemas como a dificuldade das merendeiras em diariamente terem que elaborar o alimento, por conta destes "[...] darem muito trabalho", como afirma RMCG (36 anos, merendeira). Ou como ratifica VGH (41 anos): "Sabe que é mais fácil chegar a caixinha e entregar, do que ficar na boca do fogão mexendo...mexendo...em pé um bom tempo". 
Tais afirmações integram uma gama de dificuldades que foram encontradas no processo de implantação deste item na alimentação das crianças de ensino fundamental no município de Baturité.

\section{Considerações Finais}

Pensar em estratégias de soberania alimentar é refletir sobre a importância de serem estabelecidos mecanismos de controle social, condição necessária para se atingir, plenamente, os objetivos de uma política pública de Segurança Alimentar e Nutricional (SAN). É por meio da mobilização social que se constituirá a construção de um modelo de sociedade mais equitativo, ambientalmente sustentável e que tenha a Educação e a Segurança Alimentar e Nutricional, o Direito Humano à Alimentação Adequada e a Soberania Alimentar, como eixos estratégicos de desenvolvimento social. Tal debate está diretamente vinculado a Segurança Alimentar e Nutricional e a questão da cultura alimentar, considerando ainda o fato dos pequenos produtores de alimentos tradicionais correrem 0 risco de abandonarem suas atividades produtivas e mesmo das comunidades perderem o hábito de se alimentarem com determinados produtos, quando não há um incentivo para que haja resistência sobre as formas de consumo capitalista.

O que pode-se destacar ainda é que tais reflexões apresentam caminhos para se pensar na preservação de alimentos tradicionais, ainda que fundamentadas em diferentes contextos e abordagens teóricas, estão em harmonia quanto à necessidade e relevância de valorização e proteção de formas de conhecimento tradicional, especialmente no que diz respeito aos espaços rurais, evidenciando, assim, a centralidade da preservação desses conhecimentos e, em decorrência, dos produtos - como é o caso dos alimentos tradicionais - ali gerados.

O que se percebe do levantamentos das estratégias de soberania alimentar no Ceará, é que existem formas de superação das condições adversas sejam elas climáticas, pelo fato do Ceará encontrar-se em uma área semiárida ou pela da pressão capitalista que tem focada nas transformações das formas de consumo alimentar dos sujeitos sociais.

Os movimentos sociais apresentam um papel essencial nesse processo, pois juntamente com as instituições de ensino e pesquisa, bem como as ONgs, têm promovido a divulgação de hábitos alimentares e organizações sociais que hoje apresentam-se no espaço geográfico como bandeiras de luta e resistência no que tange às estratégias analisadas nesta pesquisa, principalmente quando se observa a 
viabilidade da inserção de produtos da agricultura familiar no cotidiano da alimentação escolar de crianças do ensino fundamental e médio.

\section{REFERÊNCIAS}

AZEVEDO, Helena Selma. Segurança Alimentar: desafios na agricultura familiar e de reforma agrária. In: SALES, Celecina de $\mathrm{M}$. V. et al. Terra, sujeitos e condição agrária. Fortaleza: Imprensa Universitária. 2007. 220 p. p. 119-132, 2007.BRASIL. Ministério da Educação. Lei no 8.913, de 12 de julho de 1994. Dispõe sobre a municipalização da merenda escolar. Disponível em: http://www.planalto.gov.br/ccivil_03/leis/L8913.htm. Acessado em: mai. 2017.

BRASIL. Resolução Normativa n. 9, de 11 de dezembro de 1978. Disponível em < http://portal.anvisa.gov.br/documents/33916/394219/Resolucao 9 1978.pdf/fe774403-c2484153-bde9-43518c5295d1>.Acesso em 25 de mar. de 2019.

.Resolução/CD.FNDE no 15, de 25 de agosto de 2000. Estabelece os critérios e as formas de transferência de recursos financeiros às secretarias de educação dos estados e do Distrito Federal, às prefeituras municipais e às escolas federais, à conta do PNAEPNAE. Brasília (DF), 2000.

.Medida Provisória No 2.178-36, de 24 de Agosto de 2001. Dispõe sobre o repasse de recursos financeiros do Programa Nacional de Alimentação Escolar, institui o Programa Dinheiro Direto na Escola, altera a Lei no 9.533, de 10 de dezembro de 1997, que dispõe sobre programa de garantia de renda mínima, institui programas de apoio da União às ações dos Estados e Municípios, voltadas para o atendimento educacional, e dá outras providências. Brasília (DF), 2001.

.Resolução/CD/FNDE no 2, de 10 de janeiro de 2002. Estabelecer critérios para a transferência de recursos financeiros, à conta do PNAE, previstos na Medida Provisória ${ }^{\circ}$ 1784, de 14 de dezembro de 1998 e suas reedições e na Resolução CD/FNDE n 015, de 25 de agosto de 2000. Brasília (DF), 2002.

Resolução/CD/FNDE n. 32, de 10 de agosto de 2006. Estabelece as normas para a execução do Programa Nacional de Alimentação Escolar -PNAE. Diário Oficial da União, Brasília, 11 ago. 2006. Seção 1, p. 22.

Decreto no 7.775, de 4 de Julho de 2012. Disponível em < http://www. planalto .gov.br/ccivil_03/_Ato2011-2014/2012/Decreto/D7775.htm>. Acesso em: 23 set. 2012.

Ministério da Educação. Fundo Nacional de Desenvolvimento da Educação (FNDE). Resolução n. 26, de 17 de junho de 2013. Dispõe sobre o atendimento da alimentação escolar aos alunos da educação básica no âmbito do Programa Nacional de Alimentação Escolar - PNAE. Diário Oficial da União, Brasília, 18 jun. 2013. Seção 1, p. 7.

Resolução/CD/FNDE n. 4, de 2 de abril de 2015. Altera a redação dos artigos 25 a 32 da Resolução/CD/FNDE n. 26, de 17 de junho de 2013, no âmbito do Programa Nacional de Alimentação Escolar (PNAE). Diário Oficial da União, Brasília, 03 abr. 2015. Seção 1, p. 10. 
Aquisição de produtos da Agricultura Familiar para a alimentação escolar.

2ª ed. Brasília, 2016. Disponível em http://www.fnde.gov.br/. Acessado em: mai. 2017.

Programa Nacional de Alimentar Escolar. Disponível em: http://www.fnde.gov.br/.

Acessado em: fev. 2017.

Fundo Nacional De Desenvolvimento Da Educação. Caderno de Legislação

PNAE 2011. Conselho Regional de Nutricionistas, 2017. Disponível em:

http://www.crn1.org.br/caderno-de-legislacao-pnae-2011/. Acessado em: mai. 2017.

BEZERRA, José Arimátea Barros (Org.) . (2014). Alimentos tradicionais do Nordeste:

Ceará e Piauí. Fortaleza: Ed. UFC, 2014.

BOBBIO, Norberto; MATTEUCCI, Nicola; PASQUINO, Gianfranco. (1995). Dicionário de política. v.2. 8.ed. Brasília: UNB, 1995, 2 v. BRASIL. Ministério do Desenvolvimento Agrário (MDA). Plano Territorial de Desenvolvimento Rural Sustentável: Território Cidadania Maciço do Baturité - MDA/SDT/CONSAD Fortaleza: Instituto Agropolos do Ceará, 2010.

BASTOS, Frederico de Holanda (Org.). Serra de Baturité: uma visão integrada das questões ambientais. Fortaleza: Expressão Gráfica e Editora, 2011.

CETRA. IDT e UFPE apresentam estudo sobre Feiras Agroecológicas no Ceará. Disponível em < http://www.cetra.org.br/noticias/idt-e-ufpe-apresentam-estudo-sobre-feirasagroecologicas-no-ceara/>. Acesso em nov. 2012.

CONTRERAS, Jesús; GRACIA, Mabel. Alimentação, sociedade e cultura. Rio de Janeiro: Editora Fiocruz, 2011. 496 p.

CORDEIRO, A. FARIA A. A. Gestão de bancos de sementes comunitários. Rio de Janeiro. AS-PTA, 1993.

DaMATTA, Roberto. O que faz do brasil, Brasil?. Rio de Janeiro: Rocco, 1986.

A casa e a rua: espaço, cidadania, mulher e morte no Brasil. 5. ed. Rio de Janeiro: Rocco, 1997.

DENARDIN, Valdir Frigo; KOMARCHESKI; Rosilene (Orgs.). Farinheiras do Brasil: tradição, cultura e perspectivas da produção familiar de farinha de mandioca /

Organizadores: Valdir Frigo Denardin; Rosilene Komarcheski. - Matinhos: UFPR Litoral, 2015.

DIÁRIO DO NORDESTE. População do Ceará ultrapassa os 9 milhões de habitantes e deve parar de crescer em 24 anos. Fortaleza: Jornal Diário do Nordeste, 2018.Disponível em < https://diariodonordeste.verdesmares.com.br/editorias/metro/online/populacao-doceara-ultrapassa-os-9-milhoes-de-habitantes-e-deve-parar-de-crescer-em-24-anos$\underline{1.1974955}$. Acesso em 12 de Mar. de 2019.

ESPLAR. Casa de sementes comunitárias. 2006. Disponível em: <http://www.esplar.org.br/publicacoes/sementes.htm>, Acesso em dez., 2009.

FAO. Cartilha de Agrobiodiversidade. 1996. Disponível em $<$ http://www.centroecologico.org.br/cartilhas/cartilha_agrobiodiversidade.pdf.>.Acesso em set/2010. 
FBSSAN.(2013) Painel 2: A dimensão pública do abastecimento alimentar. Transcrição da palestra. Porto Alegre - RS, dia 04 de junho de 2013.

GEERTZ, Clifford. Thick description: toward an interpretive theory of culture. In: GEERTZ, Clifford. The interpretation of cultures. New York, Basic Books, 1973. pp. 33-32.

. Uma descrição densa: por uma teoria interpretativa da cultura. In: GEERTZ,

Clifford. A interpretação das culturas. Rio de Janeiro, Zahar, 1978. pp. 13-44.

IBGE. Censo Agropecuário 2006. Rio de Janeiro. V. 1, Brasil, 2006.

JALIL, Letícia Medeiros (2009). Mulheres e Soberania Alimentar: a luta para transformação do meio rural brasileiro. Dissertação de Mestrado. RJ: UFRJ.

LEONEL, Junia Conceição (2010). Quintais para Vida: tecnologia social no semiárido. Fortaleza: CETRA, 2010.

LIMA, A.E.F. (2008). Tocando em Frente: cultura camponesa e apropriação dos recursos naturais no Assentamento Ingá-Facundo-Parambu-CE. Dissertação (Mestrado em Desenvolvimento e Meio Ambiente - PRODEMA). Universidade Federal do Ceará. Fortaleza: UFC, 2008.

.(2015). A Geografia da Segurança Alimentar e Nutricional do Ceará: Um estudo sobre o Programa de Aquisição de Alimentos (PAA). Tese (Doutorado em Geografia). Universidade Federal do Ceará. Fortaleza: UFC, 2015. 200p.

MAPA. Pronaf leva desenvolvimento a agricultores familiares do Ceará. 15 de ago. 2016. Disponível em< http://www.mda.gov.br/sitemda/noticias/pronaf-levadesenvolvimento-agricultores-familiares-do-cear\%C3\%A1>. Acesso em 22 de mar. 2019.

MARTINS, R. C. B.; et al (2004). Aceitabilidade da Alimentação Escolar no Ensino Público Fundamental. Saúde em Revista, Piracicaba, v. 6, nº 13, p. 71-78.

MONTANARI, M. Comida como cultura. São Paulo: Senac, 2008.

MORAIS, A. C. S. Desenvolvimento, otimização e aceitabilidade de extrato hidrossolúvel da amêndoa da castanha de caju (Anacardium ocidentale L.). Dissertação (Mestrado em Ciência e Tecnologia de Alimentos). Universidade Federal do Ceará. Fortaleza: UFC, 2009. 113p.

POLLAN, Michael. O Dilema do Onívoro: Uma história natural de quatro refeições. Rio de Janeiro: Intrínseca, 2007.

REDIG, Ana; REBOUÇAS, Nadia. Ação da Cidadania 20 anos. Rio de Janeiro: 5w Editora, 2014.

REDE DE INTERCÂMBIO DE SEMENTES DA ZONA NORTE (RIS).Relatório Encontro Diocesano. Sobral-CE: RIS, 2010.

ROSSET, Peter. Food Sovereignty. Global Rallying Cry of Farmers Movements. Food First - Institute for Food and Development Policy. Backgrounder, Vol. 9, № 4, 2003. 
TIBÉRIO, M.L. Produtos tradicionais: importância socioeconômica na defesa do mundo rural. 1a Jornada de Queijos e Enchidos - Produtos Tradicionais. IAAS, EXPONOR, p. 1-13, 1998.

VASCONCELOS, José Maria Gomes (2011). Implantação de casas de sementes comunitárias como forma de sustentabilidade alimentar e preservação da biodiversidade vegetal no Sertão Cearense. Monografia (Especialização em Agroecologia) - Instituto de Estudos e Desenvolvimento Humano (leducare), Sobral, 2011.

VASCONCELOS, F. de A. G. de: Fome, solidariedade e ética: uma análise do discurso da Ação da Cidadania contra a fome, a Miséria e pela Vida. História, Ciências, Saúde Manguinhos, vol. 11(2): 259-77, maio-ago. 2004.

ZUIN, Poliana Bruno; ZUIN, Luís Fernando Soares. Produção De Alimentos Tradicionais Contribuindo Para O Desenvolvimento Local/Regional E Dos Pequenos Produtores Rurais. In: Revista Brasileira de Gestão e Desenvolvimento Regional- G\&DR • v. 4, n. 1, p. 109127, jan-abr/2008, Taubaté, SP, Brasil. Disponível em < http://www.rbgdr.net/012008/artigo5.pdf>. Acesso em 25 de mar. De 2019.

Tradição e Alimentação. Aparecida, SP: Ideias \& Letras, 2009.

Alimentação é cultura: aspectos históricos e culturais que envolvem a alimentação e o ato de se alimentar. Nutrire, 2009b.

XAVIER, Leonardo Pereira Xavier et. all. Braz. J. of Develop., Curitiba, v. 4, n. 7, Edição Especial, p. 4454-4466, nov. 2018.

\section{NOTAS DE AUTOR}

Anna Erika Ferreira Lima - Concepção. Coordenação do Projeto no IFCE - Campus Baturité.Coleta de dados, Análise de dados, Elaboração do manuscrito, revisão e aprovação da versão final do trabalho. José Levi Furtado Sampaio- Elaboração do manuscrito. Análise das informações. Participação na discussão dos resultados; Revisão e aprovação da versão final do trabalho.

Márcia Maria Leal de Medeiros - Elaboração do manuscrito. Análise das informações. Participação na discussão dos resultados; Revisão e aprovação da versão final do trabalho.

Rafaela Maria Temóteo Feuga - Elaboração do Manuscrito referente ao tópico do Doce de Goiaba em Pasta, bem como a aplicação da análise sensorial; Revisão e aprovação da versão final do trabalho.

\section{FINANCIAMENTO}

Edital PROINFRA 13/2013 - PRPI - IFCE.

CONSENTIMENTO DE USO DE IMAGEM

Não se aplica

\section{APROVAÇÃO DE COMITÊ DE ÉTICA EM PESQUISA}

Não se aplicou à época.

\section{CONFLITO DE INTERESSES}

Não se Aplica.

\section{LICENÇA DE USO}

Este artigo está licenciado sob a Licença Creative Commons CC-BY. Com essa licença você pode compartilhar, adaptar, criar para qualquer fim, desde que atribua a autoria da obra.

\section{HISTÓRICO}

